\title{
Determination of shale types using well logs
}

\begin{abstract}
Determination of shale type in shale formation has long been a difficult task. Presence of shales in some of the Iranian reservoir formations are one of the most important subject. Shale types have to be considered, because existence of shale type reduces, effective porosity and permeability of the reservoir to some extent. Allogenic Shale is distributed in formations in three basic types, Dispersed, Laminar and structural. Each of these shale types has different effect on porosity, permeability and water saturation. Dispersed shale type reduces effective porosity and permeability to a great extent, but, laminar and structural have less effect on petrophysical parameters. In this investigation, shale types, Shale volume and effective porosity of shale formations have been determined from well logs based on cross-plotting. In other words, a triangle Density-Neutron cross-plot is used to determine the above parameters. The area of study chosen from central oil fields of Iran, where some of the wells are used (Tabnak Field). Tabnak Well C selected for this study in Kangan Formation, South Pars. This study illustrates that distribution of shale types in Kangan Formation is mainly dispersed shale with few of laminar shale, and the quality of effective porosity $\left(\varphi_{\mathrm{e}}\right)$ decreases with increasing depth in the Kangan Formation.
\end{abstract}

Keywords: shaley formation, shale types, cross-plotting, kangan formation, well $\operatorname{logs}$
Volume 2 Issue 5 - 2017

\section{Ghassem Alaskari MK, Roozmeh A}

Department of Petroleum Engineering, Petroleum University of Technology, Iran

Correspondence: Ghassem Alaskari MK, Department of Petroleum Engineering, Petroleum University of Technology, Iran, Email ghassemal@gmail.com

Received: February, 2017 | Published: June 27, 2017

\section{Introduction}

Shale is a fine-grained sedimentary rock usually composed of $50 \%$ silt $(3.9-62.5 \mu \mathrm{m}), 35 \%$ clay $(0.98-3.9 \mu \mathrm{m})$ and $15 \%$ other fine clastic particles (feldspars, quartz, carbonates, zircon, etc.). Shale is distributed in reservoir formations in three basic types, structural, laminar, dispersed or combination of these three types. Each type of shale is described as given in Ghorab. ${ }^{1}$

\section{Structural shale}

Exists in the form of fragments or crystals which are an integral part of the rock framework. In other words, is considered as a portion of rock matrix. This mode of shale distribution has no effect on porosity or permeability. ${ }^{2}$

\section{Laminar shale}

Exists as layer of clay minerals within clean formations (i.e. sandstone, carbonate, etc). The effect of this type on porosity and permeability is sometimes severe and should be investigated.

\section{Dispersed shale}

Dispersed shale is composed of clay minerals, fragments or crystals which usually found on grain surface, occupying pore spaces between particles. Dispersed shale will include both detritus and diagenetic clay minerals. One or both of these forms may be present in this type shale. This type of shale reduces effective porosity and permeability to a great extent.

Considerable portion of shale consists of clay minerals such as illite, kaolinite, chlorite, montmorillonite, and etc. Clay minerals in reservoir formation have severe effects on petrophysical properties and reduce the effective and total porosities as well as permeability of the reservoir. Also, shale causes serious problems in formation evaluation and drilling operations. ${ }^{3}$
Shale affects all well logging measurements to some degree. ${ }^{4}$ With using well logging data, presence of shale in a formation can be recognized. Besides, shale types, shale volume and effective porosity can be determined either graphically (Cross-plotting) or analytically using Gamma ray spectrum (CGR).

\section{Methodology}

In this investigation, Vsh estimated from cross-plot method is compared with $\mathbf{V}_{\mathrm{sh}}$ calculated from Gamma ray spectrum (CGR).

\section{Shale volume $\left(V_{s h}\right)$ calculated from gamma ray spectrum}

In this paper, Vsh estimated from cross-plot method is validated with $\mathbf{V}_{\text {sh }}$ calculated from Gamma ray spectrum (CGR). CGR is the best and most accurate method for determining shale volume. The following equations are used to calculate shale volume.

$I G R=\frac{C G R_{\mathrm{log}}-C G R_{\min }}{C G R_{\max }-C G R_{\min }}, \quad C G R=A \log t h+B L \operatorname{og} K$

i. IGR is the Gamma ray index

ii. $\mathbf{C G R}_{\log }$ is the Gamma ray spectrum in the zone of interest

iii. $\mathbf{C G R}_{\text {min }}$ is the Gamma ray spectrum in cleanest formation

iv. $\mathbf{C G R}_{\text {max }}$ is the Gamma ray spectrum in shale zone

v. A and B are Log calibration constants

Then, the shale volume $\left(\mathrm{V}_{\mathrm{sh}}\right)$ can be calculated from the Gamma ray index, by the following formula;

$$
\begin{aligned}
& V_{\text {sh }}=0.33\left[2^{(2 \times I G R)-1.0}\right] \text { for hard formation } \\
& V_{\text {sh }}=0.083\left[2^{(3.7 \times I G R)}-1.0\right] \text { for soft formation }
\end{aligned}
$$


$\mathbf{V}_{\mathbf{s h}}=\mathbf{I G R} /$ [3-2IGR] for gas saturated formation [4]

\section{Hydrocarbon correction}

More accurate method to correct for hydrocarbon effect on density and neutron porosities before points are plotted on cross-plot are given below: ${ }^{6}$

For the neutron porosity

$$
\varphi_{\text {Ncorr }}=\varphi_{N}-\Delta \varphi_{N}
$$

Where

$$
\begin{aligned}
& \Delta \varphi_{N}=\varphi S_{h r} \frac{\rho_{h}-0.7+0.4 P}{1-0.4 P} \text { For oil } \\
& \Delta \varphi_{N}=\varphi S_{h r} \frac{2.2_{\rho h}-0.7+0.4 P}{1-0.4 P} \text { For gas }
\end{aligned}
$$

In fresh mud (less than $50000 \mathrm{ppm}$ ) the equation can be reduced to:

$\Delta \varphi_{N}=\varphi S_{h r}(\rho h-0.7)$ for oil

$$
\Delta \varphi_{N}=\varphi S_{h r}(2.2 . \rho h-1.0) \text { for gas }
$$

And

P is salinity of the mud in PPM

$\varphi_{\mathrm{N}}$ is neutron porosity

$\varphi_{\text {Ncorr }}$ is corrected neutron porosity

$\boldsymbol{\rho}_{\boldsymbol{h}}$ is hydrocarbon density

$S_{h r}$ is residual oil saturation

\section{For the density porosity}

$$
\varphi d c o r r=\varphi d-\Delta \varphi d
$$

Where,

$$
\begin{aligned}
& \varphi_{d}=\left(\rho_{m a}-\rho_{b)} /\left(\rho_{m a}-\rho_{f}\right)\right. \\
& \Delta \varphi_{d}=1.07 \varphi S_{h r} \frac{\left(1.11\left(1-\rho_{h}\right)+0.65 P-0.03\right)}{\rho_{m a}-1.0-0.7 P} \text { for oil } \\
& \Delta \varphi_{d}=1.07 \varphi S_{h r} \frac{1.11-0.65 P-1.24 \rho_{h}}{\rho_{m a}-1.0-0.7 P} \text { for gas }
\end{aligned}
$$

In salinity less than $50000 \mathrm{ppm}$ (fresh mud) the parameter, P can be considered zero. An estimation of hydrocarbon density $\rho_{h}$ can be obtained by the following equations.

$$
\begin{gathered}
\rho_{h=} \frac{0.7 \times\left(1+\frac{\varphi_{n}}{\varphi_{d}}\right) S_{h r-\left(1-\frac{\varphi_{n}}{\varphi_{d}}\right)} \text { for oil saturated }}{\left(1+0.72 \frac{\varphi_{n}}{\varphi_{d}}\right) S_{h r}} \\
\rho_{h=} \frac{\left(1+0.72 \frac{\varphi_{n}}{\varphi_{d}}\right) S_{h r-\left(1-\frac{\varphi_{n}}{\varphi_{d}}\right)} \text { for gas saturated }}{\left(2.2+0.8 \frac{\varphi_{n}}{\varphi_{d}}\right) S_{h r}}
\end{gathered}
$$

Residual hydrocarbon saturation is used, because the neutron and density tools investigate the flushed zone. The saturation in the flushed zone is calculated based on the Archie's equation.

$$
\left.S_{x o}=\sqrt{\left(\frac{a}{\varphi^{m}}\right.} \times \frac{R_{m f}}{R_{x o}}\right)=\sqrt{\frac{F R_{m f}}{R_{x o}}} \text { and } S_{h r}=1-S_{x o}
$$

$\varphi$ is porosity of the formation

$\mathbf{m}$ is cementation factor

a is lithology constant

$\mathbf{R}_{\mathrm{mf}}$ is resistivity of mud filtrate

$\mathbf{R}_{\mathrm{x} 0}$ is resistivity of flushed zone (micro resistivity tool response)

\section{Shale volume $\left(\mathrm{V}_{\mathrm{sh}}\right)$ estimated from cross-plot (CP)}

Generally, cross-plot is a quick and commodious method for estimation of shale volume and shale types with acceptable accuracy in comparison with other methods, such as core and log analysis. ${ }^{7}$ $\mathrm{XRD}$ is one the exact methods for clay mineral determination. ${ }^{8}$

In this cross-plot three distinct points $(\mathrm{F}, \mathrm{M}, \mathrm{SH})$ are shown Figure 1. Point $\mathbf{F}$ represents fluid or water point, where $\varphi_{D}=\varphi_{N}=100 \%$. Point $\mathbf{M}$ represents matrix point. If density and neutron tools are calibrated in term of the existing matrix, then $\varphi_{N}=\varphi_{D}=0$. Point $\mathbf{S H}$ represents shale point. The coordinate of point $\mathbf{S H}\left[\varphi_{N S h}, \varphi_{D S h}\right]$ must be determined for shaley portion of well and this coordinate vary from well to well and have to be estimated for each case. ${ }^{9}$

\section{Effective porosity $\left(\varphi_{\mathrm{e}}\right)$ estimated from cross-plot (CP)}

Line $\mathbf{M}-\mathbf{F}$ represents clean formation or $\mathrm{V}_{\mathrm{sh}}=0$ line. This line is scaled in effective porosity as shown in Figure 1. Points representing $\varphi_{N}$ and $\varphi_{D}$ values in clean formations will fall on $\mathbf{M}-\mathbf{F}$ line and their position on the line indicate effective porosity values. Line M-SH represents $\varphi_{e}=0$ line and value of each point on this line indicates shale volume of the formation that has no effective porosity. Points that represent shaley formation fall within triangle. Because porosity values do not exceed $50 \%$, line $\mathbf{M}-\mathbf{F}$ is plotted till $50 \%$ porosity to make full use of cross-plot. ${ }^{10}$ Following equations have been used to construct this triangle.

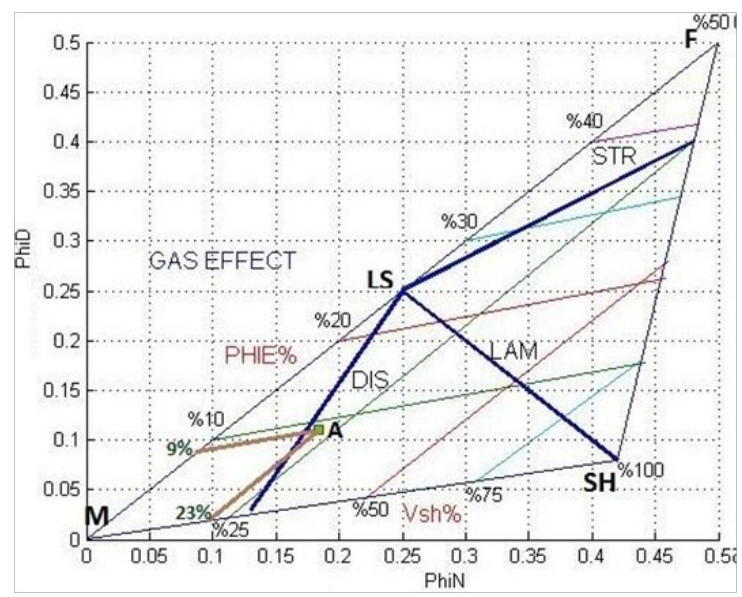

Figure I Triangle neutron-density porosity cross-plot.

$$
\varphi_{e}=\varphi_{n}-\left(\varphi_{N S h .} V_{s h}\right), \varphi_{e}=\varphi_{d}-\left(\varphi_{D s h . V_{s h}}\right)
$$


In Figure 1 laminar shale points fall on LAM or around LS-SH line, dispersed shale points fall on or around DIS line and structural shale point's fall on or around STR line.

For each point within triangle $\mathrm{V}_{\mathrm{Sh}}$ is estimated on $\mathbf{M}-\mathbf{S H}$ line parallel to clean formation line (diagonal line), and also, $\varphi_{e}$ is determined on clean formation line parallel to $\mathbf{M}-\mathbf{S h}$ line. For example point $\mathbf{A}$ in

Figure 1 represents a shaley formation that has values of $\varphi_{e}=9 \%$ and $\mathrm{V}_{\mathrm{Sh}}=23 \%$. Shale type for this point is dispersed. ${ }^{11}$

If formation contains hydrocarbon, Neutron and Density porosities have to be corrected before points are plotted, by using the equations (4-17).

\section{Determination of shale types in kangan formation}

There are five depths interval selected for this study from Kangan Formation, well-C Figure 2. The results for each interval have been given below.

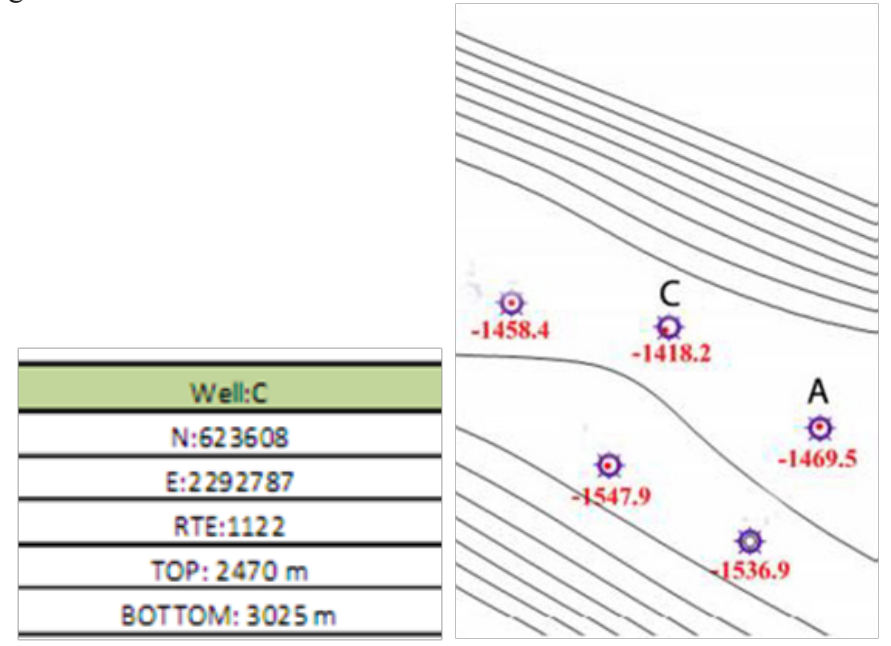

Figure 2 Location of well-C in Tabnak field.

\section{Depth intervals "2590-2592m"}

This interval of formation has considerable volume of shale and saturated with formation water Figure 3. After plotting measured points of this interval on cross-plot Figure 4 is seen that aggregation of points is around laminar shale line. So, distribution mode of shale for this section of formation is laminar. Vsh and $\varphi_{e}$ estimated from cross-plot for each point of this interval are given in Table 1.

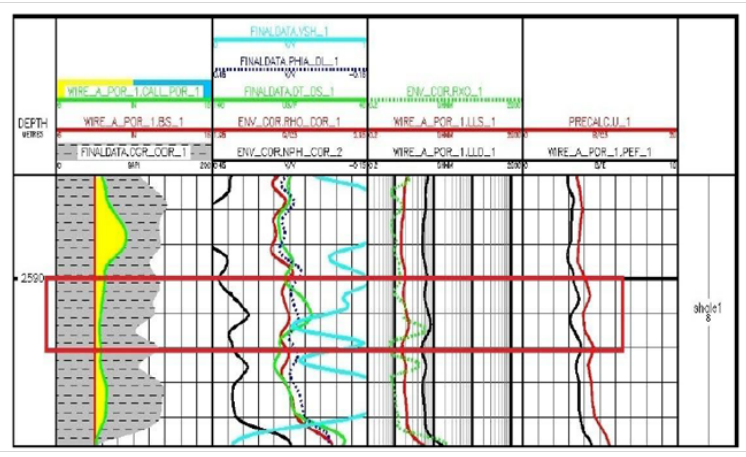

Figure 3 Full set log data for 2590-2592m depth interval.

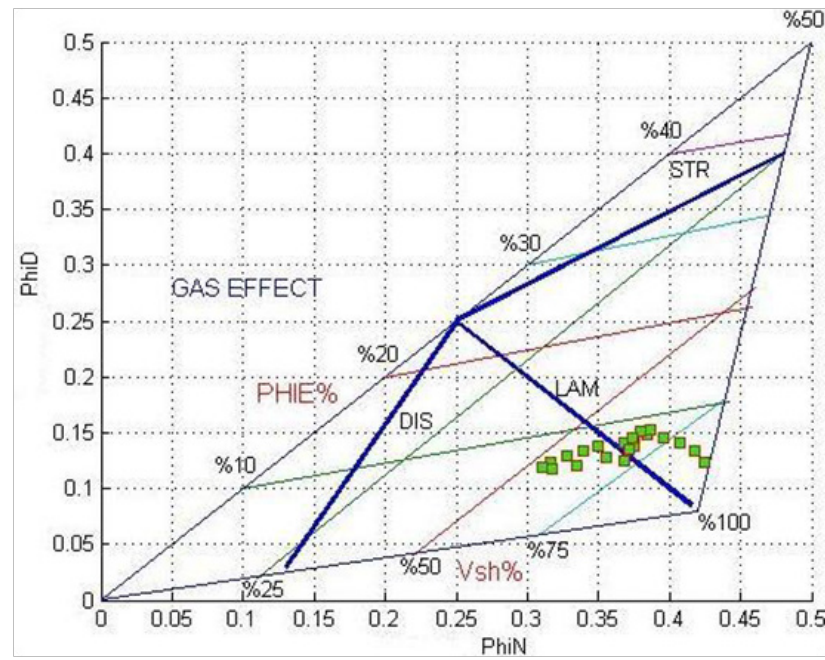

Figure 4 Neutron-density porosity cross-plot for 2590-2592m depth interval.

Table I $\mathrm{V}_{\text {sh }}$ and PHIE $\left(\varphi_{\mathrm{e}}\right)$ estimated from cross-plot $(\mathrm{CP})$ for depth interval $2590-2592 \mathrm{~m}$

\begin{tabular}{|c|c|c|c|}
\hline PHI-N & PHI-D & PHIE-CP & $v_{s h}-C P$ \\
\hline 0.424 & 0.122 & 0.051 & 0.88 \\
\hline 0.417 & 0.133 & 0.067 & 0.83 \\
\hline 0.407 & 0.141 & 0.079 & 0.78 \\
\hline 0.395 & 0.145 & 0.085 & 0.73 \\
\hline 0.375 & 0.144 & 0.09 & 0.67 \\
\hline 0.367 & 0.141 & 0.088 & 0.66 \\
\hline 0.35 & 0.137 & 0.088 & 0.62 \\
\hline 0.339 & 0.133 & 0.085 & 0.6 \\
\hline 0.328 & 0.128 & 0.081 & 0.58 \\
\hline 0.315 & 0.123 & 0.087 & 0.56 \\
\hline 0.309 & 0.119 & 0.074 & 0.56 \\
\hline 0.317 & 0.117 & 0.07 & 0.58 \\
\hline 0.335 & 0.12 & 0.069 & 0.63 \\
\hline 0.355 & 0.127 & 0.074 & 0.67 \\
\hline 0.374 & 0.138 & 0.082 & 0.69 \\
\hline 0.384 & 0.148 & 0.092 & 0.69 \\
\hline 0.387 & 0.153 & 0.098 & 0.68 \\
\hline 0.379 & 0.152 & 0.098 & 0.67 \\
\hline 0.373 & 0.144 & 0.091 & 0.67 \\
\hline 0.371 & 0.134 & 0.078 & 0.69 \\
\hline 0.365 & 0.125 & 0.067 & 0.71 \\
\hline
\end{tabular}

\section{Depth intervals “2650.3-2652"}

This section has no shale and there is gas in formation Figure 5. So, neutron and density porosities must be corrected for hydrocarbon effect. Figures 6, Figure 7 shown positions of points before and after 
correcting hydrocarbon effect for neutron and density porosities on cross-plot and is seen that points fall on clean formation line after hydrocarbon correction. For this interval, $\varphi_{e}$ estimated from crossplot, corresponds to 15.2 to $16.8 \%$ Table 2 and effective porosity measured with core analysis method is 17.1 to $18.2 \%$. As one can be seen, this result is very close together, and therefore, this method can be applied to estimate effective porosity with acceptable accuracy. $\mathrm{V}_{\mathrm{sh}}$ and $\varphi_{e}$ determined from cross-plot for each point of this interval are given in Table 2.

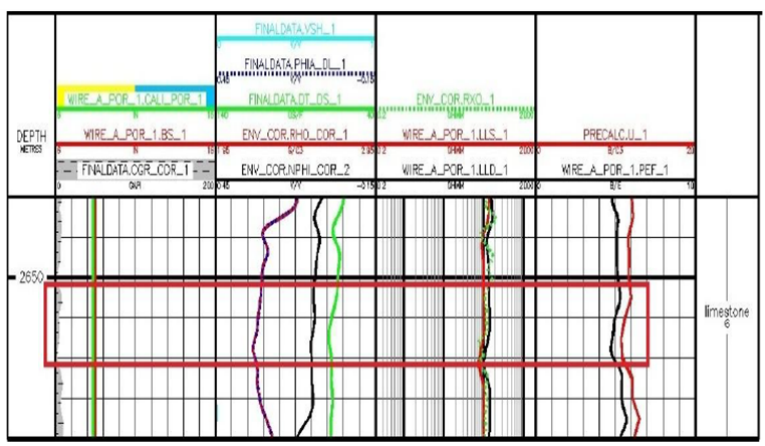

Figure 5 Full set log data for 2650.3-2652m depth interval.

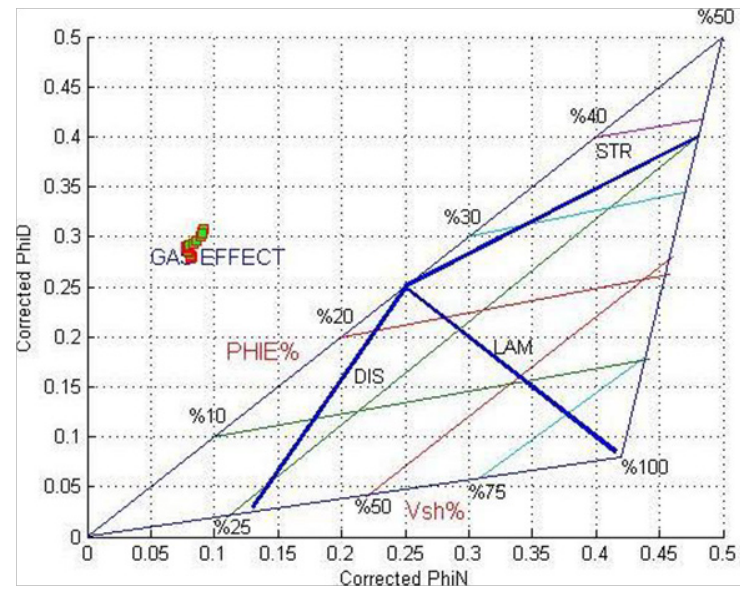

Figure 6 Neutron-Density porosity cross-plot for $2650.3-2652 m$ depth interval (before gas correction).

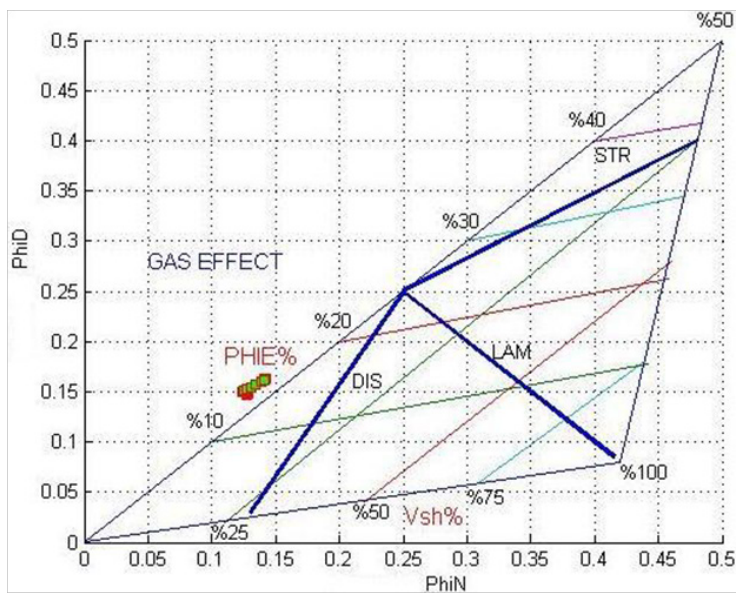

Figure 7 Neutron-density porosity cross-plot for 2650.3-2652m depth interval (after gas correction).
Table $\mathbf{2} \mathbf{V}_{\text {sh }}$ and PHIE $\left(\varphi_{\mathrm{e}}\right)$ estimated from cross-plot $(\mathbf{C P})$ for depth interval 2650.3-2652m

\begin{tabular}{llll}
\hline PHIN-COR & PHID-COR & PHIE-CP & $\mathbf{V}_{\text {sh }}-C P$ \\
\hline 0.127 & 0.147 & 0.152 & 0 \\
0.127 & 0.148 & 0.152 & 0 \\
0.128 & 0.148 & 0.153 & 0 \\
0.127 & 0.149 & 0.153 & 0 \\
0.126 & 0.149 & 0.154 & 0 \\
0.125 & 0.15 & 0.155 & 0 \\
0.124 & 0.15 & 0.156 & 0 \\
0.124 & 0.15 & 0.156 & 0 \\
0.125 & 0.151 & 0.157 & 0 \\
0.127 & 0.152 & 0.158 & 0 \\
0.13 & 0.153 & 0.159 & 0 \\
0.134 & 0.156 & 0.161 & 0 \\
0.138 & 0.159 & 0.164 & 0 \\
0.141 & 0.162 & 0.167 & 0 \\
0.142 & 0.163 & 0.168 & 0 \\
\hline & & &
\end{tabular}

\section{Depth intervals " 27 | 8.5-27 | 9.5m"}

This interval of formation has intermediate volume of shale and saturated with formation water Figure 8. After plotting measured points of this interval on cross-plot Figure 9 we seen that points occupy the area between laminar and dispersed shale lines. So, distribution mode of shale for this section of formation is combination of laminar and dispersed types. Vsh and $\varphi_{\mathrm{e}}$ estimated from cross-plot for each point of this interval and are given in Table 3.

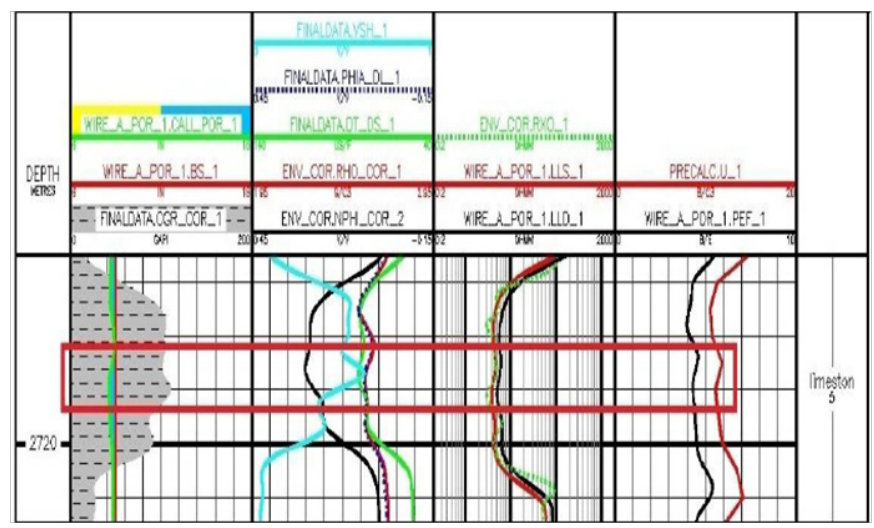

Figure 8 Full set log data for 27/8.5-27/9.5m depth interval.

With comparing $\mathbf{V}_{\text {sh }}$. estimated from cross-plot method and $\mathbf{V}_{\text {sh }}$ calculated from gamma ray (with using of CGR) is seen that these values are very close together for each point Figure 10, therefore, cross-plot method can be used to determine shale volume and effective porosity with acceptable accuracy. 


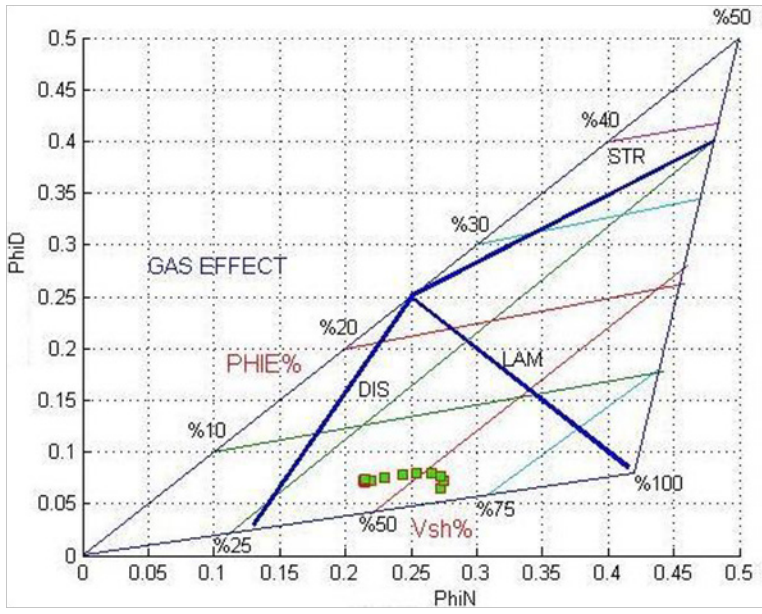

Figure 9 Neutron-density porosity cross-plot for $2718.5-27 \mid 9.5 \mathrm{~m}$ depth interval.

Table $3 \mathbf{V}_{\mathrm{sh}}$ and PHIE $\left(\varphi_{\mathrm{e}}\right)$ estimated from cross-plot for $2718.5-2719.5 \mathrm{~m}$ depth interval

\begin{tabular}{llllll}
\hline Depth & PHI-N & PHI-D & PHIE & $\mathbf{V}_{\text {sh }}$-CP & VSH-CGR \\
\hline 2718.5 & 0.272 & 0.065 & 0.017 & 0.607 & 0.557 \\
2718.6 & 0.274 & 0.072 & 0.024 & 0.595 & 0.604 \\
2718.7 & 0.272 & 0.077 & 0.031 & 0.574 & 0.62 \\
2718.8 & 0.264 & 0.079 & 0.036 & 0.545 & 0.593 \\
2718.9 & 0.254 & 0.079 & 0.038 & 0.513 & 0.534 \\
2719 & 0.244 & 0.077 & 0.038 & 0.489 & 0.466 \\
2719.1 & 0.23 & 0.074 & 0.038 & 0.458 & 0.411 \\
2719.2 & 0.219 & 0.071 & 0.037 & 0.434 & 0.376 \\
2719.3 & 0.214 & 0.071 & 0.037 & 0.422 & 0.363 \\
2719.4 & 0.214 & 0.072 & 0.038 & 0.418 & 0.368 \\
2719.5 & 0.215 & 0.074 & 0.04 & 0.414 & 0.384 \\
\hline
\end{tabular}

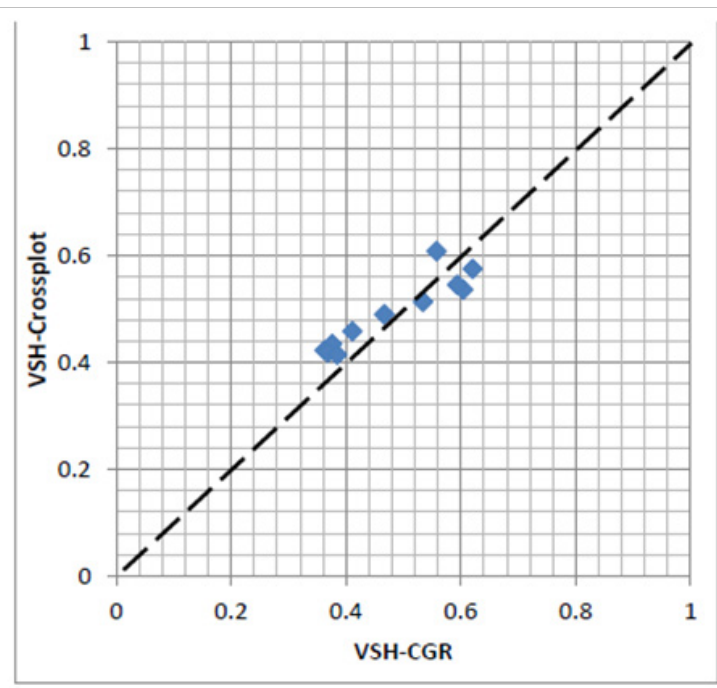

Figure $10 \mathbf{V}_{\mathrm{sh}}$ estimated from cross-plot and $\mathbf{V s h}$. calculated from -gamma ray spectrum (CGR) for depth interval 27।8.5-27I9.5m (Accuracy: 94 - 99\%).

\section{Depth intervals " $2730.5-2731.5 \mathrm{~m}$ "}

This section of formation has intermediate volume of shale and saturated with formation water Figure 11. After plotting measured points of this interval on cross-plot Figure 12 is seen that aggregation of points is around dispersed shale line. So, distribution mode of shale for this section of formation is dispersed. Vsh and $\varphi_{\mathrm{e}}$ estimated from cross-plot for each point of this interval and are given in Table 4.

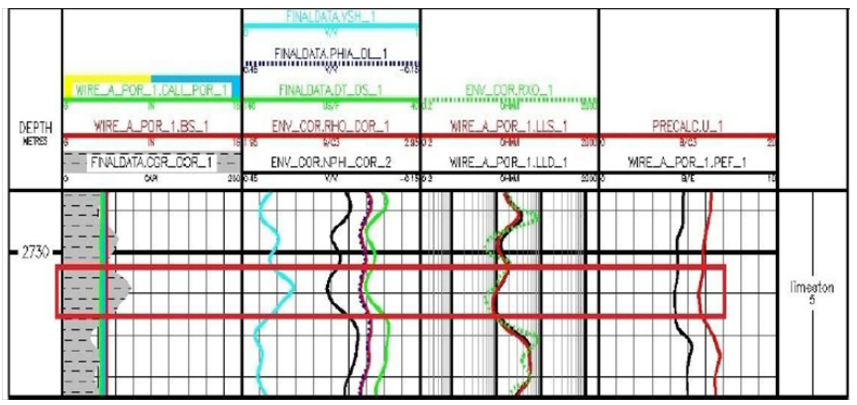

Figure I I Full set log data for 2730.5-2731.5m depth interval.

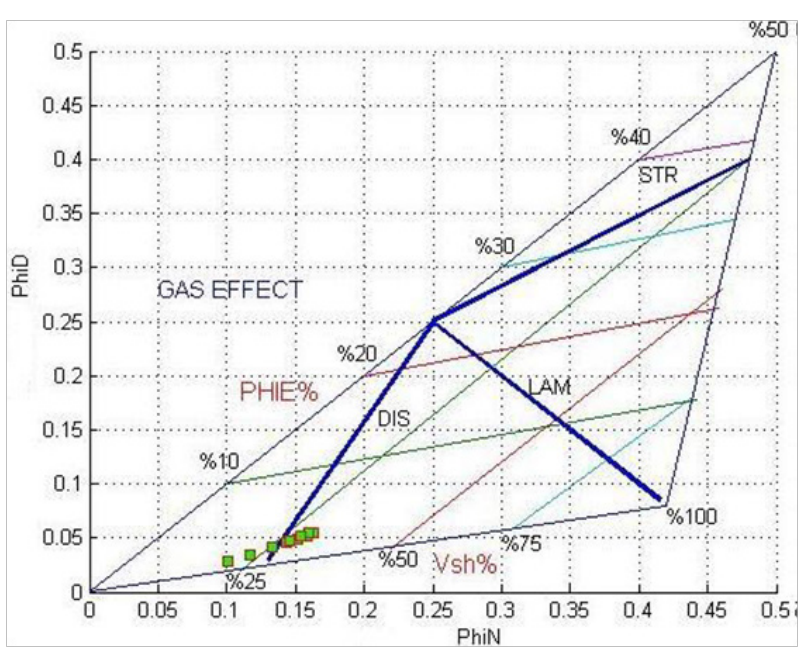

Figure 12 Neutron-density porosity cross-plot for $2730.5-2731.5 \mathrm{~m}$ depth interval.

Table $4 \mathbf{V}_{\text {sh }}$ and PHIE $\left(\varphi_{\mathrm{e}}\right)$ estimated from cross-plot (CP) for 2730.5$2731.5 \mathrm{~m}$ depth interval

\begin{tabular}{llllll}
\hline Depth & NPHI & PHID & PHIE-CP & VSH-CP & VSH-CGR \\
\hline 2730.5 & 0.142 & 0.045 & 0.022 & 0.286 & 0.207 \\
2730.6 & 0.151 & 0.049 & 0.024 & 0.302 & 0.239 \\
2730.7 & 0.158 & 0.052 & 0.027 & 0.312 & 0.27 \\
2730.8 & 0.162 & 0.054 & 0.028 & 0.319 & 0.289 \\
2730.9 & 0.163 & 0.055 & 0.029 & 0.318 & 0.289 \\
2731 & 0.159 & 0.054 & 0.029 & 0.31 & 0.272 \\
2731.1 & 0.154 & 0.051 & 0.027 & 0.301 & 0.247 \\
2731.2 & 0.145 & 0.047 & 0.024 & 0.288 & 0.224 \\
2731.3 & 0.132 & 0.041 & 0.019 & 0.27 & 0.205 \\
2731.4 & 0.117 & 0.034 & 0.014 & 0.243 & 0.19 \\
2731.5 & 0.1 & 0.027 & 0.011 & 0.214 & 0.171 \\
\hline
\end{tabular}


With comparing $\mathbf{V}_{\text {sh }}$ estimated from cross-plot and $\mathbf{V}_{\text {sh }}$ calculated from gamma ray (with using of CGR) is seen that these values are very close together for each point Figure 13, therefore, cross-plot method can be used to determine shale volume and effective porosity with acceptable accuracy. ${ }^{12}$

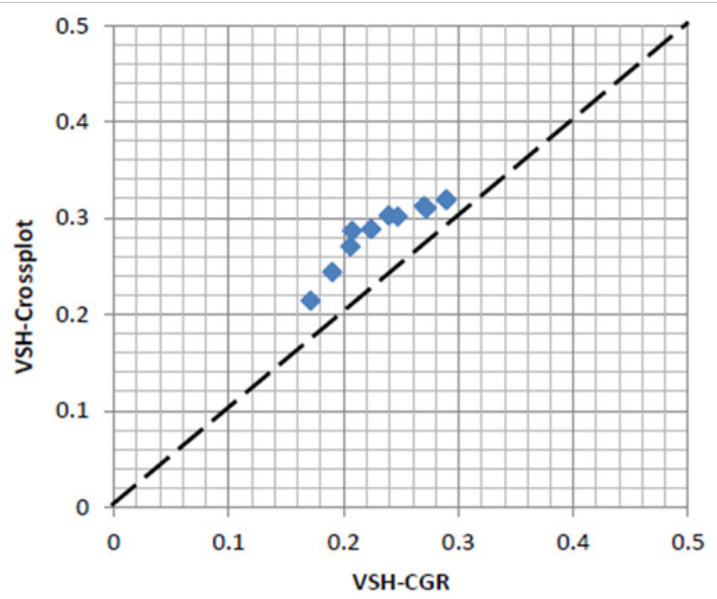

Figure $13 \mathbf{V}_{\text {sh }}$ estimated from cross-plot and $\mathbf{V}$ sh calculated from gamma ray spectrum (CGR) for 2730.5-2731.5m depth interval (Accuracy: 89.7-97\%).

\section{Depth intervals “2743-2744m”}

This interval of formation has low volume of shale and saturated with formation water Figure 14. After plotting measured points of this interval on cross-plot Figure 15 we seen that aggregation of points is around dispersed shale line. So, distribution mode of shale for this section of formation is dispersed. $\mathrm{V}_{\mathrm{sh}}$ and $\varphi_{\mathrm{e}}$ estimated from cross-plot for each point of this interval and are given in Table 5.

Table 5 $\mathbf{V}_{\text {sh }}$ and PHIE $\left(\varphi_{\mathrm{e}}\right)$ estimated from cross-plot(CP) for depth interval $2743-2744 \mathrm{~m}$

\begin{tabular}{llllll}
\hline Depth & $\begin{array}{l}\text { NPHI- } \\
\text { COR }\end{array}$ & $\begin{array}{l}\text { PHID- } \\
\text { COR }\end{array}$ & $\begin{array}{l}\text { PHIE- } \\
\text { CP }\end{array}$ & $\begin{array}{l}\text { VSH- } \\
\text { CP }\end{array}$ & $\begin{array}{l}\text { VSH- } \\
\text { CGR }\end{array}$ \\
\hline 2743 & 0.087 & 0.043 & 0.033 & 0.128 & 0.136 \\
2743.1 & 0.1 & 0.048 & 0.036 & 0.152 & 0.155 \\
2743.2 & 0.112 & 0.052 & 0.038 & 0.174 & 0.171 \\
2743.3 & 0.119 & 0.055 & 0.04 & 0.189 & 0.181 \\
2743.4 & 0.121 & 0.056 & 0.041 & 0.193 & 0.184 \\
2743.5 & 0.118 & 0.055 & 0.04 & 0.186 & 0.178 \\
2743.6 & 0.11 & 0.052 & 0.038 & 0.171 & 0.165 \\
2743.7 & 0.099 & 0.047 & 0.035 & 0.152 & 0.146 \\
2743.8 & 0.088 & 0.041 & 0.031 & 0.136 & 0.125 \\
2743.9 & 0.077 & 0.036 & 0.026 & 0.121 & 0.106 \\
2744 & 0.068 & 0.032 & 0.024 & 0.105 & 0.09 \\
\hline
\end{tabular}

With comparing $\mathbf{V}_{\text {sh }}$ estimated from cross-plot and $\mathbf{V}_{\text {sh }}$ calculated from gamma ray (with using of CGR) is seen that these values are very close together for each point Figure 16, therefore, cross-plot method can be used to determine shale volume and effective porosity with acceptable accuracy.

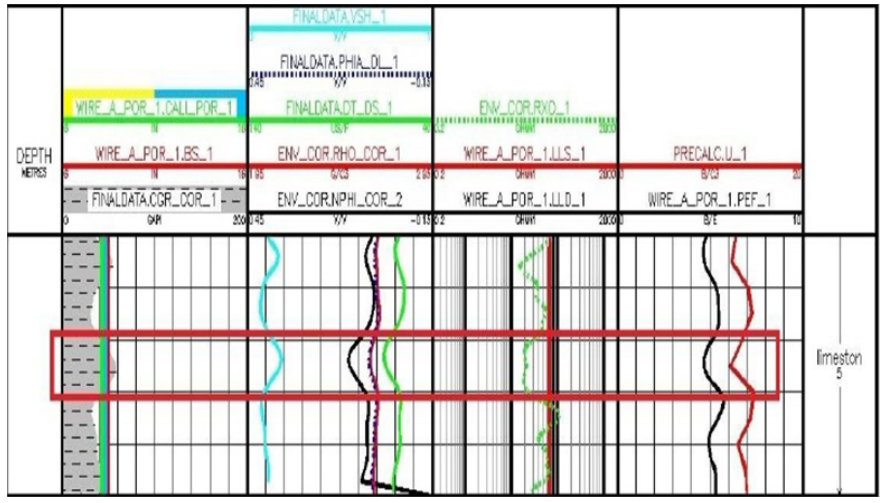

Figure I 4 Full set log data for 2743-2744m depth interval.

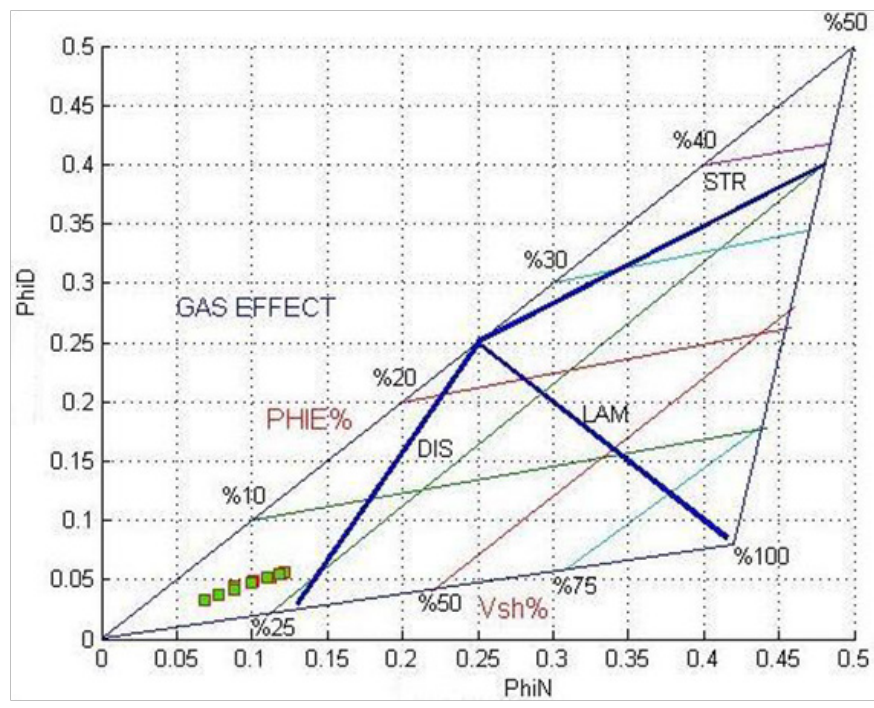

Figure I5 Neutron-density porosity cross-plot for 2743.-2744m depth interval.

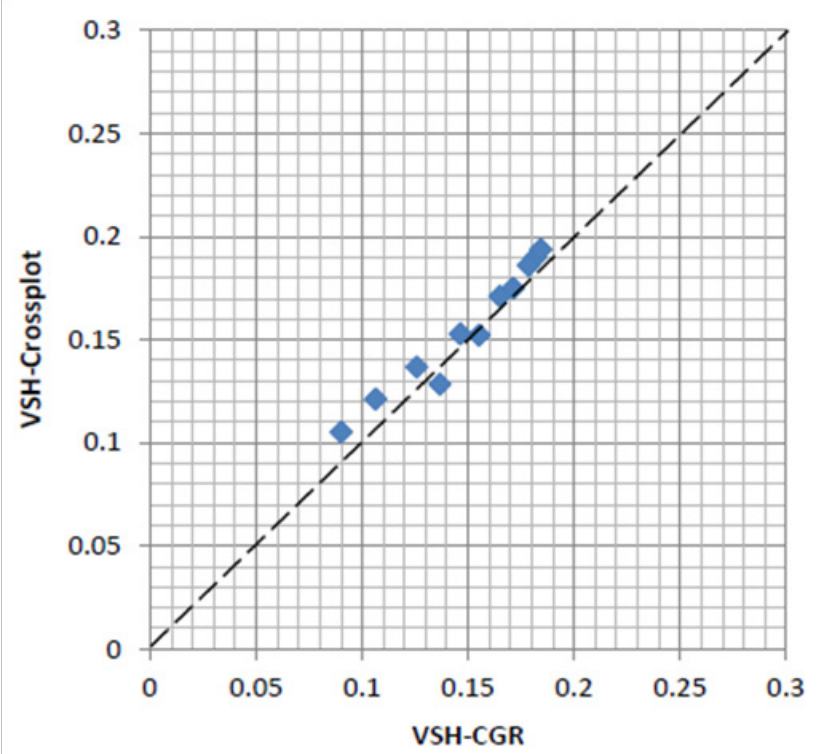

Figure $16 \mathbf{V}_{\text {sh }}$ estimated from cross-plot method and $\mathbf{V}$ sh calculated from gamma ray spectrum (CGR) for depth interval 2743-2744m (Accuracy: 98.599.7\%). 


\section{Results and discussion}

This investigation is done for many depth intervals of Tabnak Well $\mathrm{C}$ in Kangan Formation, central Iranian oil field. By using distribution of shale types for each interval, shale volume and the effective porosity for each point have been estimated by cross-plotting method. A triangle neutron-density porosity cross-plot has been applied for this purpose.

i. For data sets used in this investigation the range of accuracy for determining shale volume using CGR and CP are $89.7 \%$ to $99.7 \%$.

ii. This study illustrates distribution of shale types in K-Formation mainly dispersed shale with few of laminar shale.

iii. Based on effective porosity estimated in this investigation, reservoir quality decreases with increasing depth in K-Formation.

$\mathbf{V}_{\text {sh }}$ estimated from cross-plot has been validated with $\mathbf{V}_{\mathrm{sh}}$ calculated by Gamma ray spectrum using equations (1) and (3) in unsaturated shale and equation (4) in gas saturated shale. Also, $\varphi_{\mathrm{e}}$ estimated using cross-plotting method has been compared with $\varphi_{\mathrm{e}}$, measured by well logs. In shaley formations saturated with hydrocarbon, equations (4) to (17) have been used for correction of shale volume and effective porosity. It is seen that, these shale volumes are very close together. Therefore, cross-plotting method can be used to determine shale volume and effective porosity with acceptable accuracy.

Cross-plotting is a quick and commodious method in comparison with other methods, such as core analysis or well logs for determining petrophysical parameters.

This method can be used for any formation which has shaley layers using cross-plotting of $\varphi_{N S h}$ versus $\varphi_{D S h}$ in each depth interval. Shale types should be determined and recalibrated after a few well has been drilled. The results of this method can be used to estimate productivity and capacity of a reservoir.

\section{Conclusion}

a. Cross-plotting method can be used for determination of shale types, shale volume, and effective porosity with acceptable accuracy.

b. In case of structural shale, correction for effective porosity is not necessary, but depends on type of clay minerals in this shale type.

c. In case of Laminated and dispersed types corrections for Vsh and PHIE are essential. d. In case of gas saturated shale of any type, correction is needed.

\section{Acknowledgements}

None.

\section{Conflict of interest}

The author declares no conflict of interest.

\section{References}

1. Ghorab M, Ramadan MA, Nouh A. The Relation Between the Shale Origin (Source or non Source) and its Type for Abu Roash Formation at Wadi El- Natrun Area, South of Western Desert, Egypt. Australian Journal of Basic and Applied Sciences. 2008;2(3): 360-371.

2. Ruhovets N, Fertl WH. Volumes, Types, and Distribution of Clay Minerals in Reservoir Rocks Based on Well Logs. SPE Unconventional Gas Recovery Symposium, Pittsburgh, Pennsylvania, USA; 1982.

3. Bassiouni Z. Theory, measurement, and interpretation of well logs. Doherty Memorial Fund of AIME, Society of Petroleum Engineers, Texas, USA, 1994

4. Serra O. Fundamentals of well-log interpretation. USA: Elsevier Science Publishing Company Inc; 1984.

5. Stieber S. Pulsed Neutron Capture Log Evaluation - Louisiana Gulf Coast. SPE paper 2961, Fall Meeting of the Society of Petroleum Engineers of AIME. Houston, Texas, USA, 1970.

6. Brock J. Applied open- Hole log analysis. USA: Gulf publishing company; 1986.

7. Tiab DC, Donaldson E. Petro physics: Theory and Practice of Measuring Reservoir Rock and Fluid Transport Properties. USA: Gulf Professional Publishing; 2004.

8. Ghassem Alaskari MK. Petrophysical Lab Testing. Tehran: Institute of Rahenovin; 2016.

9. Ghassem Alaskari MK. Analysis of Shaley reservoir zones and their effects on logging tools for Interpretation of Reservoir Parameters in Coastal Fars fields of Iran. ICOFC, Iran; 2012.

10. Bigelow El. Introduction to Wireline Log Analysis. Houston, Western Atlas International, USA; 1992

11. Dresser Atlas. Well logging and interpretation techniques. USA: Dresser ind inc; 1982.

12. Worthington PF. The Evolution of Shaly-sand Concepts in Reservoir Evaluation. The Log Analyst. 1985;26(1):23-40. 